\title{
The Effects of a Marine Leisure Exhibition Event's Appraisal Attributes on Visitors' Satisfaction and Re-visit Intention
}

\author{
+ WoO-Jeong Cho \\ + Dept. of Ocean Physical Education, Korea Maritime University, Busan 606-791, Korea
}

\begin{abstract}
The purposes of this study were to analyze the effects of a marine leisure exhibition event(MLEE)'s appraisal attributes on visitors' satisfaction and rep-visit intention and thus provide fundamental information that facilitates developing effective marketing and operational strategies for a MLEE. In order to accomplish such purposes, this study employed a survey with a total of 300 visitors to a MLEE hosted by G Province. Questionnaires were developed on the basis of related studies and modified to reflect the study context. Then, such questionnaires were verified to be valid and reliable through content validity, factor analysis and internal consistency analysis. Valid 286 questionnaires were analyzed with correlation analysis and multiple regression analysis on significance level of .05. Following findings were derived from current study. First of all, the appraisal attributes of a MLEE had a significant effect on visitors' satisfaction and among them only the factor of event program had a unique relation with the levels of satisfaction. In addition, the appraisal attributes of the MLEE also had a significant effect on visitors' rep-visit intention behavior and among them event program, transportation and employee factors had unique relations with the performance variable in order. In conclusion, all the research hypotheses that had been set up through previous studies were confirmed in this study.
\end{abstract}

Key words : marine leisure exhibition event, appraisal attributes, satisfaction, re-visit intention and event marketing

\section{Introduction}

The marine leisure industry is predicted to experience the continuous growth and development despite the worldwide economic downturn in these days. Therefore, both central and regional governments and related cooperations show a great amount of interest and investment in activating the industry for the utilization of associated industry sectors as an economic momentum and regional development measure(Marine Southeast, 2009).

Especially, a variety of marine leisure events have been hosted by regional governments to effectively promote the industry and establish residents' supports through publicizing the values of the industry. Among others, a marine leisure exhibition event is analyzed not only to play a driving force role in developing marine leisure industry sectors such as marine leisure equipment industry but also contribute to its further development as an important industry sector itself(GRI, 2009; KNDI, 2008).

However, marine leisure exhibition events(hereafter MLEE) in our country are being evaluated to maintain relatively low levels of competitiveness and to be in a rudimentary state, while they have been fostered as a mean of creating substantial economic benefits as well as diverse social and cultural benefits in society. In addition, hosting bodies, mainly regional governments, are concerned with MLEE's economic values but display few efforts to maximize such potentialities. It is also identified as a critical problem that few attempts to evaluate how well goals and objectives of hosting a MLEE are accomplished are realized in the event marketing and management process.

Therefore, current study is initiated to analyzed the effects of MLEE's appraisal attributes on visitors' satisfaction and rep-visit intention behavior and to provide fundamental information that could facilitate developing marketing and management strategies for a MLEE to be successful.

\section{Theoretical Frameworks}

A MLEE's appraisal attributes are properties providing evaluation standards and they are multilateral and multidimensional. That is, a MLEE can be evaluated by several constituents such as host city, event organizer, business sector and visitors. Moreover, evaluation indexes are varied based on types of evaluators or constituents.

Kang(2005) insisted that in order to objectively evaluate an event, varied constituents' opinions should be reflected including visitors, residents, organizers and businesses. Additionally, Kim(2005) proposed that evaluating an event

\footnotetext{
† Corresponding Author, mikecho@hhu.ac.kr 051) 410-4794
} 
The Effects of a Marine Leisure Exhibition Event's Appraisal Attributes on Visitors' Satisfaction and Re-visit Intention

should be divided into visitors and experts who have their unique evaluation indicators. Moon \& Cho(2011) emphasized the importance of evaluating an event from visitors' perspectives which determine levels of an event's effectiveness.

However, each researcher has a different definition of appraisal attributes for an event that may be determined by its types and characteristics. Ko et al.(2010) utilized such variables as program entertainment, diversity, experience, cultural aspect and tangible product's price as to evaluate an event. Moon et al.(2008) attempted to evaluate an event based on an event's facility, operation, information, product, interest, price and so on. Plus, Lee(2003) assessed an event using marketing mix factors such as product, price, place and promotion but Choi \& Jin(2009) stressed an event's abstract properties such as convenience, experience and systemicity. Ahn et al.(2007) employed factors including family friendliness, escape of daily life, education and sociability, which were so abstract that an event organizer could not apply in planning and operating the event. In contrast, Jang(2005) conceptualized an event's appraisal attributes using program, transportation, service, facility, shopping and food which may be assessed by the perceptions of visitors. Yoon(2009) also utilized facility, operation, service, publicity and transportation in evaluating an exhibition event and provided the attributes' priority. Thus, this study attempts to synthesize factors developed by previous research(Jang, 2005; Kim, 2005; Yoon, 2009). In specific, each factor of appraisal attributes was selected based on the criterion such as practicality suggested by Ministry of Culture \& Tourism(2003), which means that factors of appraisal attributes should not be abstract but practical for event organizers to utilize in establishing operating strategies for an event.

Meanwhile, following research hypotheses are constructed based on previous research dealing with the relationships between an event's appraisal attributes and visitors' satisfaction or repurchase behavior.

First of all, it has been revealed through empirical research that there is a relationship between an event's appraisal attributes and visitors' satisfaction(Ko et al., 2010; Ahn et al., 2007; Jang, 2005; Choi \& Jin, 2009; Mohr, Backman, Gahan \& Backman, 1993). For example, Ko et al.(2010) and Moon et al.(2008) reported that a festival event's appraisal attributes had significant effects on visitors' satisfaction, and Ko(2009), Ryu \& Lee(2009) and Moon \& Cho(2011) reported that a sport event's appraisal or selection attributes were empirically related to satisfaction.
Especially, Lee \& Kim(2008) reported that all of appraisal attributes including event operation had unique relations with visitors' satisfaction. Accordingly, based on previous research, the first research hypothesis is derived as follows.

H1: MLEE's appraisal attributes will have positive effects on visitors' satisfaction

Researchers have examined the relationship between appraisal attributes and $\mathrm{re}^{-}$visit intention and regarded it as an important paradigm that needs to be identified to better induce more numbers of visitors to an event(Kim, 2007; Moon \& Cho, 2011; Ahn et al., 2007; Yeo et al., 2006). In addition, Choi \& Jin(2009) further reported that an event's appraisal attributes were related to not only levels of visitors' satisfaction but also positive perceptions and attitudes towards the event and host city. Moon et al.(2008) verified that levels of perceived appraisal attributes determined visitors' satisfaction and willing to pay in the future event. $\operatorname{Jang}(2005)$ indirectly demonstrated the relationship between two variables by reporting that high levels of appraisal attributes would result in visitors' loyalty and their loyalty would accrue to repurchase behavior. Accordingly, as indicated previously, the second hypothesis is derived as follows.

H2: MLEE's appraisal attributes will have positive effects on visitors' re-visit intention.

\section{Methodology}

\subsection{Survey Participants and Procedures}

The participants in the present study were visitors including domestic and foreign to an international yacht show hosted by Kyongnam Province in 2010 October. After taking a permission from the organizing committee, a total of 300 questionnaires were distributed at the exhibition event site using convenience sampling method. In an effort to better reflect the characteristics of the event visitors, all types of visitors were surveyed including people who participated in the event for the purposes of tour, business and education or conference. As a result, valid 286 ques- $^{-}$ tionnaires were analyzed after deleting 14 incomplete questionnaires. The characteristics of survey participants are shown in Table 1. 
Table 1 The characteristics of participants

\begin{tabular}{cccc}
\hline \multicolumn{2}{c}{ Classification } & Freq. & Pct. (\%) \\
\hline \hline \multirow{2}{*}{ Gender } & Male & 159 & 55.6 \\
& Female & 127 & 44.4 \\
\hline \multirow{4}{*}{ Age } & $20^{\prime}$ s & 62 & 21.7 \\
& 30 's & 57 & 19.9 \\
& $40^{\prime}$ s & 80 & 28.0 \\
& Over 50's & 87 & 30.4 \\
\multirow{2}{*}{ Residence Out } & Kyongnam & 133 & 46.5 \\
& Oversea & 69 & 29.4 \\
\hline \multirow{2}{*}{ Visiting } & Tour & 191 & 24.1 \\
Purpose & Business & 42 & 66.7 \\
& Conference & 53 & 14.8 \\
\hline
\end{tabular}

\subsection{Instrumentation}

In order to measure the visitors' levels of perceived appraisal attributes, satisfaction and re-visit intention, a self-assessment questionnaire developed on the basis of previous research was utilized after modification. First of all, the appraisal attributes questionnaire consists of 7 sub variables including transportation, facility, cost, employee, accommodation, publicity and program(see Table 2), which were all retrieved from appraisal factors utilized by Kim(2005), Bae(2008) and Jang(2005). In addition, visitors' satisfaction and $\mathrm{re}^{-}$visit intention scales include 4 item each other. These two scales were adapted from the previous study(Ko, 2009) and measured through 5 point Likert scale such as 1 for "Never Agree", 5 for "Always Agree".

In order to confirm validity and reliability of the instrument, content validity, factor analysis and internal consistency analysis were performed in this study. Sub factors and items, which were developed based on the previous research mentioned above, were checked for representativeness and appropriacy by a panel of experts. Also, English version questionnaires for foreign visitors were validated by a bilingual expert who verified the connotation and consistency between Korean and English versions. Then, a factor analysis with principal component analysis and varimax rotation method was conducted as seen Table 3. As a result, the result indicated that 7 factors of the modified instrument were confirmed in the data collected from this study and a total of 21 items explained $75.72 \%$ of variance for the instrument. Meanwhile, reliability analyses indicated that all scales had sufficient alpha levels, appraisal attributes, .755 .846, satisfaction, .860 and repurchase behavior, .768 .
Table 2 Operational definitions of appraisal attributes

\begin{tabular}{|c|c|c|}
\hline Variable & operational definition & item \\
\hline Facility & $\begin{array}{l}\text { facilities that event visitors utilize } \\
\text { during their visits including } \\
\text { exhibition booth, rest lounge, toilet } \\
\text { and so on }\end{array}$ & $\begin{array}{l}\text { event venue } \\
\text { rest area } \\
\text { amenities }\end{array}$ \\
\hline Transportation & $\begin{array}{l}\text { means of transportation's } \\
\text { convenience and approachableness } \\
\text { including parking convenience and } \\
\text { public transit's approachableness }\end{array}$ & $\begin{array}{l}\text { approachableness } \\
\text { convenience of parking } \\
\text { public transportation }\end{array}$ \\
\hline Cost & $\begin{array}{l}\text { expenses that visitors pay during } \\
\text { their visits including food price, } \\
\text { amenity price and souvenir }\end{array}$ & $\begin{array}{l}\text { inexpensive souvenir } \\
\text { food price } \\
\text { amenity price }\end{array}$ \\
\hline Employee & $\begin{array}{l}\text { employees's attitudes toward } \\
\text { visitors such as kindness and levels } \\
\text { of pre education. }\end{array}$ & $\begin{array}{c}\text { employee' } \\
\text { kindness } \\
\text { trained employee } \\
\text { sufficient number of } \\
\text { employee }\end{array}$ \\
\hline Accommodation & $\begin{array}{l}\text { buildings where visitors stay and } \\
\text { their cleanliness, convenience and } \\
\text { distance from event site }\end{array}$ & $\begin{array}{c}\text { cleanliness } \\
\text { reservation's } \\
\text { convenience } \\
\text { distance from event site }\end{array}$ \\
\hline Program & $\begin{array}{l}\text { programs' interest and variety to } \\
\text { satisfy visitors' needs and providing } \\
\text { visitors with in-person experiencing } \\
\text { opportunities }\end{array}$ & $\begin{array}{c}\text { even interest } \\
\text { event diversity } \\
\text { experience program }\end{array}$ \\
\hline Publicity & $\begin{array}{l}\text { information and materials intended } \\
\text { to attract visitors' attention }\end{array}$ & $\begin{array}{l}\text { pre publicity } \\
\text { information booth } \\
\text { information brochure }\end{array}$ \\
\hline
\end{tabular}

\subsection{Data Treatment}

Along with intercorrelations among study variables, descriptive statistics was calculated to show the nature of data collected from valid 286 questionnaires using SPSS 18.0. Then, a set of multiple regression analyses were utilized to estimate the effects of $\mathrm{MLEE}^{\prime}$ appraisal attributes on visitors' satisfaction and repurchase behavior. In addition, both $\mathrm{R}^{2}$ and regression coefficients were tested at the significance level of .05.

\section{Findings}

\subsection{Descriptive Statistics and Intercorrelations among Variables}

As indicated by Table 4, the mean scores for most of appraisal attributes were located between 'So So' and 'Agree' on a 5 point Likert scale. In specific, the mean scores for 'Program(M=3.53, $\mathrm{SD}=.80)^{\prime}$, 'Employee( $\mathrm{M}=3.48$, $\mathrm{SD}=.78)^{\prime}$, and 'Publicity $(\mathrm{M}=3.40, \mathrm{SD}=.83)^{\prime}$ were relatively higher than those for 'Facility $(\mathrm{M}=3.34, \quad \mathrm{SD}=.78)^{\prime}$, 'Accommodation $(\mathrm{M}=3.34, \mathrm{SD}=.70)^{\prime}, \quad$ ' $\operatorname{Cost}(\mathrm{M}=3.36, \mathrm{SD}=.69)^{\prime}$ 
The Effects of a Marine Leisure Exhibition Event's Appraisal Attributes on Visitors' Satisfaction and Re-visit Intention

Table 3 Factor analysis and Cronbach's a tests of appraisal attributes

\begin{tabular}{|c|c|c|c|c|c|c|c|c|}
\hline Item & 1 & 2 & 3 & 4 & 5 & 6 & 7 & $\begin{array}{c}\text { Commu- } \\
\text { nality }\end{array}$ \\
\hline event venue & .781 & .136 & .183 & .143 & .124 & .121 & .192 & .654 \\
\hline rest area & .741 & .201 & .111 & .226 & .056 & .202 & .097 & .706 \\
\hline amenities & .689 & .212 & .154 & .170 & .176 & .201 & .101 & .749 \\
\hline event interest & .235 & .807 & .130 & .046 & .235 & .126 & .239 & .665 \\
\hline event diversity & .117 & .794 & .009 & 0.97 & .246 & .114 & .022 & .703 \\
\hline $\begin{array}{l}\text { experience } \\
\text { program }\end{array}$ & .221 & .768 & .166 & .163 & .153 & .159 & .119 & .721 \\
\hline $\begin{array}{c}\text { employee's } \\
\text { kindness }\end{array}$ & .199 & .086 & .866 & .316 & .135 & .090 & .045 & .695 \\
\hline $\begin{array}{l}\text { trained } \\
\text { employee }\end{array}$ & .208 & .045 & .776 & .121 & .229 & .250 & .147 & .821 \\
\hline $\begin{array}{l}\text { sufficient } \\
\text { number }\end{array}$ & .080 & .156 & .718 & .047 & .130 & .120 & .294 & .776 \\
\hline $\begin{array}{c}\text { sufficient } \\
\text { pre publicity }\end{array}$ & .217 & .109 & .122 & .853 & .214 & .056 & .143 & .768 \\
\hline $\begin{array}{l}\text { information } \\
\text { booth }\end{array}$ & .195 & .160 & .098. & .809 & .123 & .113 & .171 & .871 \\
\hline $\begin{array}{l}\text { information } \\
\text { brochure }\end{array}$ & .155 & .219 & .268 & .549 & .062 & .152 & .095 & .737 \\
\hline cleanliness & .359 & .403 & .246 & .218 & .797 & .081 & .142 & .775 \\
\hline $\begin{array}{l}\text { reservation's } \\
\text { convenience }\end{array}$ & .076 & .190 & .263 & .229 & .786 & .199 & .055 & .717 \\
\hline $\begin{array}{l}\text { distance from } \\
\text { event site }\end{array}$ & .115 & .148 & .067 & .097 & .678 & .058 & .277 & .734 \\
\hline approachableness & .300 & .299 & .085 & .096 & .088 & .761 & .169 & .751 \\
\hline $\begin{array}{l}\text { convenience of } \\
\text { parking }\end{array}$ & .300 & .091 & .267 & .005 & .064 & .679 & .047 & .785 \\
\hline $\begin{array}{c}\text { public } \\
\text { transportation }\end{array}$ & .319 & .152 & .208 & .197 & .057 & .619 & .156 & .804 \\
\hline $\begin{array}{l}\text { inexpensive } \\
\text { souvenir }\end{array}$ & .005 & .271 & .091 & 169 & .154 & .227 & .783 & .701 \\
\hline food price & .240 & .173 & .287 & .193 & .205 & .116 & .758 & .876 \\
\hline amenity price & .196 & .023 & .128 & .155 & .062 & .365 & .605 & .793 \\
\hline Eigen Value & 2.731 & 2.541 & 2.440 & 2.186 & 2.181 & 2.028 & 1.794 & \\
\hline Variance(\%) & 13.004 & 12.099 & 11.621 & 10.409 & 10.387 & 9.655 & 8.554 & \\
\hline Cum. Var.(\%) & 13.004 & 25.103 & 36.724 & 47.132 & 57.419 & 67.175 & 75.719 & \\
\hline Reliability & .823 & .822 & .837 & .846 & .814 & .756 & .755 & \\
\hline
\end{tabular}

Kaiser-Meyer_Olkim $(\mathrm{KMO})=.871$ and 'Transportation $(\mathrm{M}=3.38, \mathrm{SD}=.75)^{\prime}$.

Additionally, the correlation analysis showed that 'Program' with the highest mean score among 7 explaining variables had the highest simple correlation with 'Satisfaction $(r=.313, p<.01)$ '. Then, 'Facility $(r=.235, p<.01)$ ', ${ }^{\prime} \operatorname{Cost}(r=.235, p<.01){ }^{\prime}$ and 'Publicity $(r=.226, p<.01)$ ', in order, had relatively higher correlations with Satisfaction than other appraisal attributes. Meanwhile, 'Program $(r=.486$, $p<.01)^{\prime}$ also had the highest correlation with ' $\mathrm{Re}^{-}$visit Intention' and $\operatorname{Publicity}(r=.446, \quad p<.01)$, 'Transportation $(r=.420, p<.01)^{\prime}$ and 'Facility $(r=.408, p<.01)$ factors had relatively higher correlations than others.

\subsection{The Effect of Appraisal Attributes on Visitors' Satisfaction}

As indicated by Table 5, the regression model with the use of all seven factors of appraisal attribute as predictors was statistically significant and 26\% of variance of visitors' satisfaction was explained by the seven appraisal attributes $\left(R^{2}=.260, p=.000\right)$. Meanwhile, tolerance statistic and VIP indicate that no multicollinearity existed among the independent variables in this analysis ( $\mathrm{O}^{\prime}$ Brien, 2007).

However, among them, only the factor of Program had the unique relationship with satisfaction( $\beta=.300, p=.000$ ). Again, Program had the highest zero order correlation with satisfac

tion as well as the highest mean score as seen in Table 3. As a result, this result indicates that the perceived satisfaction could have shared redundant information with other independent variables except Program. Accordingly, hypothesis 1 was accepted in this study.

\subsection{The Effect of Appraisal Attributes on Visitors' Repurchase Behavior}

As indicated by Table 6, the regression model for the effect of appraisal attributes on repurchase behavior was also

Table 4 Intercorrelations among variables and descriptive statistics

\begin{tabular}{|c|c|c|c|c|c|c|c|c|c|c|c|}
\hline Variables & $M$ & $S D$ & 1 & 2 & 3 & 4 & 5 & 6 & 7 & 8 & 9 \\
\hline Facility & 3.34 & .78 & 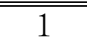 & & & & & & & & \\
\hline Transportation & 3.38 & .75 & $.640 * *$ & 1 & & & & & & & \\
\hline Cost & 3.36 & .69 & $.513 * *$ & $.553 * *$ & 1 & & & & & & \\
\hline Employee & 3.48 & .78 & $.479 * *$ & $.503 * *$ & $.528 * *$ & 1 & & & & & \\
\hline Accommodation & 3.34 & .70 & $.465 * *$ & $.391 * *$ & $.464 * *$ & $.506 * *$ & 1 & & & & \\
\hline Program & 3.53 & .80 & $.500 * *$ & $.435 * *$ & $.419 * *$ & $.368 * *$ & $.505 * *$ & 1 & & & \\
\hline Publicity & 3.40 & .83 & $.585 * *$ & $.443 * *$ & $.477 * *$ & $.469 * *$ & $.481 * *$ & $.589 * *$ & 1 & & \\
\hline Satisfaction & 3.79 & .95 & $.235 * *$ & $.206 * *$ & $.235 * *$ & $.154 *$ & $.188 * *$ & $.313 * *$ & $.226 * *$ & 1 & \\
\hline $\mathrm{Re}^{- \text {visit }}$ & 3.77 & .88 & $.408 * *$ & $.420 * *$ & $.311 * *$ & $.385 * *$ & $.369 * *$ & $.486 * *$ & $.446 * *$ & $.508 * *$ & 1 \\
\hline
\end{tabular}


statistically significant and $27.4 \%$ of variance in repurchase behavior was explained by the seven appraisal attributes as a whole $\left(R^{2}=.274, p=.000\right)$. Meanwhile, tolerance statistic and VIP also indicate that no multicollinearity existed among the independent variables in this analysis.

Three out of seven appraisal attributes had significant and unique relationships with repurchase behavior. Among them, Program had the highest unique relationship with repurchase behavior $(\beta=.293, \quad p=.000), \quad$ followed by Transportation $(\beta=.180, \quad p=.010)$ and $\operatorname{Employee}(\beta=.134$, $p=.047$ ) in order. Accordingly, hypothesis 2 was accepted as well.

Table 5 The effects of appraisal attributes on satisfaction

\begin{tabular}{cccccc}
\hline \multirow{2}{*}{ Variables } & \multicolumn{5}{c}{ Dependent Variable=Satisfaction } \\
\cline { 2 - 6 } & $\beta$ & $t$ & $p$ & Tolerance & VIP \\
\hline \hline Facility & .042 & .556 & .579 & .466 & 2.146 \\
Transportation & .111 & 1.586 & .114 & .504 & 1.983 \\
Cost & .090 & 1.305 & .193 & .555 & 1.800 \\
Employee & .123 & 1.810 & .071 & .583 & 1.716 \\
Accommodation & .039 & .584 & .559 & .590 & 1.695 \\
Program & .300 & 4.353 & .000 & .558 & 1.791 \\
Publicity & .107 & 1.479 & .140 & .511 & 1.958 \\
\hline$R / R^{2}$ & \multicolumn{5}{c}{$.510 / .260$} \\
$F / p$ & \multicolumn{5}{c}{$F=13.850, p=.000$} \\
\hline
\end{tabular}

Table 6 The effects of appraisal attributes on re-visit intention

\begin{tabular}{cccccc}
\hline \multirow{2}{*}{ Variables } & \multicolumn{5}{c}{ Dependent Variable=Re-Visit } \\
\cline { 2 - 6 } & $\beta$ & $t$ & $p$ & Tolerance & VIP \\
\hline \hline Facility & .005 & .073 & .942 & .467 & 2.139 \\
Transportation & .180 & 2.600 & .010 & .550 & 1.819 \\
Cost & .060 & .886 & .377 & .566 & 1.767 \\
Employee & .134 & 1.996 & .047 & .583 & 1.715 \\
Accommodation & .043 & .656 & .512 & .612 & 1.635 \\
Program & .293 & 4.298 & .000 & .566 & 1.768 \\
Publicity & .079 & 1.104 & .270 & .509 & 1.963 \\
\hline$R / R^{2}$ & \multicolumn{5}{c}{$.524 / .274$} \\
$F / p$ & \multicolumn{5}{c}{$F=14.914, p=.000$} \\
\hline
\end{tabular}

\section{Discussion \& Conclusion}

\subsection{Discussion}

The descriptive statistics indicated that most of appraisal attributes factors were located between 'So So' and 'Agree' at 5 point Likert scale, which means the levels of predictors were not substantially enough for us to conclude that the MLEE was being successfully hosted. Especially, the mean scores for facility, cost and transportation factors were relatively lower than those for program, employee and publicity. These findings also imply that the host city and event organizer should show more attention and investment in establishing aggressive marketing and operational strategies that could facilitate achieving the event's hosting purposes more effectively(Yoon, 2009; In, 2010).

The first hypothesis was accepted in this study and thus this finding provides further validation on previous research(Getz, 1997; Kim, 2007; Ryu \& Lee, 2009; Lee \& Kim, 2008; Mohr et al., 1993). However, among seven independent variables, the program factor was found to be the only influential predictor of visitors' satisfaction in this study. This finding is different from previous research(Ko, 2009; Moon et al., 2008; Jang, 2005). For example, Ko(2009)'s research, which attempted to evaluate the effectiveness of hosting a sport event, reported several influential factors on satisfaction including facility, operation and publicity. Moon et al.(2008) also reported that such appraisal attributes as facility and program had the significant effects on overall satisfaction. Meanwhile, Jang $(2005)^{\prime}$ research indicated that visitors' satisfaction was influenced by factors including program, transportation, service, facility and so on.

These findings suggest several event marketing implications. First, the program factor that was the most influential factor on satisfaction is the core product in setting up marketing strategies, which the MLEE host city and organizer should pay most attention to(Ko et al., 2010; In, 2010). In this regard, the host city and event organizer need to concentrate on meeting visitors' varied and diversified needs by providing such programs as equipment and product exhibition or show, education and conference, water based leisure experience and other promotional events(GRI, 2009). However, the problem is that the appraisal level of program was markedly lower than that of other exhibition events reported in other research(e.g., Yoon, 2009).

Therefore, it is strongly recommended that the host city and organizer need to differentiate their event program components and contents based on types of visitors or purposes of visiting when they are planning a MLEE. Ko et al.(2010) insisted that a successful event program's attributes include entertainment, diversity, experience, cultural orientation, and tangible products which 
all accrue to a high level of visitors' satisfaction with the event. Ahn et al.(2007) also contended that a MLEE's programs should be discriminated based on visitors' lifestyles such as family friendlyness, education, sociability and pursuit for special experience, which $\mathrm{de}^{-}$ termine motives to visit a specific event.

The second hypothesis was also accepted in this study, hypothesizing that the MLEE's appraisal attributes would have significant effects on re-visit intention including intention to revisit and recommendation. Thus, this finding provides further evidence set up by previous research(Ko, 2009; Kim, 2007; Ahn et al., 2007; Moon \& Cho, 2011; Jang, 2005; Choi \& Jin, 2009). In particular, it was emphasized in this study that such factors as program, transportation and employee should be critically considered for a MLEE to induce sufficient numbers of visitors to the event, which are an important index to evaluating its effectiveness. Again, the factor of program was the most influential factor not only on the level of visitors' satisfaction but also the intention to revisit and recommendation. This finding eventually suggests that for a MLEE's program to be successful, factors such as visitors' motives and lifestyles(Ahn et al.), purposes of visit and patterns of consuming(Yoon, 2009; Yeo et al., 2006) should be considered to reflect and meet the needs and wants of visitors to an event.

Meanwhile, the factor of transportation had a relatively higher effect on repurchase behavior than other influential factors. To this end, Yoon(2009) argued that visitors value approachableness from accommodation to event site, diversity in means of transportation and distance from airport to event site. Additionally, Choi \& Jin(2009) reported that event sites should have properties such as easiness of parking, convenience of traffic line and accessibility to event site that may decide levels of both satisfaction and $\mathrm{re}^{-}$visit intention.

However, indicated previously, the transportation fac ${ }^{-}$ tor had the lowest mean score along with facility and cost factors. In reality, the MLEE's location was evaluated for visitors to experience inconvenience because of its lack of transportation requirements suggested by Yoon(2009). It may be understandable that the host city and event organizer selected the site because it had been analyzed to have better conditions such as sufficient exhibition space and related industries, but they did not give enough consideration to transportation requirements such as site's accessibility. Therefore, it is strongly recommended that the event organizer should have proper consultation with the host city and government in order to secure convenience in transportation. A marketing maxim, 'location, location and location' provides further importance of selecting a better event site that fulfills the requirement of accessibility.

Finally, the finding indicated that among others the employee factor also had a significant effect on re-visit intention and this result provides further validation on previous research(Ko, 2009; Choi \& Jin, 2009). In this regard, Moon \& Cho(2011) asserted that an event's employees including operators and volunteers are a critical resource that determines the effectiveness of hosting the event and the positive image of the hosting city, which most host cities or regions are attempting to achieve through hosting a variety of events. That is, it is recommended that creating an organic cooperation system among employees, arranging sufficient employees and providing quality employee service should be the event organizer's priority in planning and operating an event. However, the reality is that a MLEE with varied programs has difficulties in placing enough and well trained employees who are likely to provide quality service for visitors' satisfaction and affirmative attitude to the host city as well as the event. Therefore, the event organizer needs to educate employees to be communicative, informative and service-oriented in advance, and to secure competent human resources it is necessary for the organizer to create cooperative relationships with related entities such as universities, businesses and governments(Ko, 2009).

\subsection{Conclusion}

This research was initiated to analyze the effects of a MLEE's appraisal attributes on visitors' satisfaction and

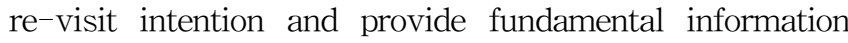
that could facilitate developing marketing and management strategies for a successful MLEE. In order to $\mathrm{ac}^{-}$ complish such purposes, a survey was conducted with 300 visitors to the MLEE hosted by Kyoungnam Province in 2010 and following findings were derived after descriptive statistic and multiple regression analyses.

First, all of the MLEE's appraisal attributes were situated between 3.34 and 3.53 at 5 point Likert scale, which means their mean scores were not substantial compared with previous research.

Second, only the program among appraisal attributes was the influential factors on visitors' satisfaction.

Third, three variables, such as program, transportation 
and employee were found to be the best predictors of revisit intention of the MLEE's visitors.

Therefore, this study hypothesizing that the MLEE's appraisal attributes would have significant effects on satisfaction and revisit intention provides further validation on previous research.

However, this study's limitations accruing from research design and method can provide several implications for future research.

First, in order to effectively deduct marketing and operating strategies for a MLEE, a systematic approach to evaluate the event should be continued including research efforts to provide a multilateral evaluation model.

Second, a MLEE has a lot of stakeholders and thus the event needs to be assessed by such constituents as host city officials, event organizers, industry sectors and visitors. In other words, developing specific appraisal attributes based on the constituents should be preceded more objective evaluation of an event.

Third, the scope of current study was limited to dealing with visitors' appraisal attributes, but evaluating a MLEE includes multidimensional aspects including social, cultural and economic. Thus, future research need to cover a synthetic approach to evaluate such aspects.

Finally, this empirical analysis had a limitation in that only some of independent variables was proven to have a causal relationship with the dependent variables. Thus, in order to more effectively analyze such relationships among variables used in this study, mediation and/or moderation effects should be identified by using a structural equation model analysis.

\section{References}

[1] Ahn, K.M., Chang, Y., \& Kim, J.Y.(2007). The study on relation between evaluation of world ceramic biennale, satisfaction and revisit intention. Korean Journal of Convention Research, 7(2), 93-105.

[2] Bae, M.K.(2008). A comparative study on the visitors' evaluation for regional festival activation. Korean Journal of Tourism Research, 23(1), 81-99.

[3] Choi, H., \& Jin, Y.J.(2009). An investigation of the relationships between evaluation attributes of festival and emotional experiences, satisfaction and positive attitudes. Korean Journal of Tourism and Hospitality Research, 23(2), 261-278.

[4] Getz, D.(1997). Event management and event tourism. Elmsford, NY: Cognizant Communication Corporation.
[5] GRI(2009). 2008 G-marine festival evaluation and development strategies. Research Paper.

[6] In, S.W.(2010). A study on analyzing sport events' objective based operating process and modeling. 48 KAHPERD Conference Proceding, 61-91.

[7] Jang, Y.L.(2005). Effects of an festival microscopic appraisal attributes on visitors' satisfaction and royalty. Culture \& Tourism Research, 7(2), 163-180.

[8] Kang, H.S.(2005). A study on the evaluation system of festival used by multi face evaluation system. Event \& Convention Research, 1, 1-22.

[9] Kim, C.(2005). A study on the evaluation model of cultural tourism festival event. Korean Journal of Tourism Management, 9(1), 73-90.

[10] Kim, J.H.(2007). A study on the evaluation of tourist satisfaction of regional festival. Korean Journal of Hotel \& Tourism Research, 9(4), 160-173.

[11] KNDI(2008). 2008 Policies advisory tasks. A Synthetic Research Paper.

[12] Ko, D.W., Boo, S.H., \& Ham, S.J.(2010). The comparative analysis of local festivals through evaluation factors with an emphasis upon Taebaek Festivals. Korean Journal of Tourism and Hospitality Research, 24(3), 143-157.

[13] Ko, H.S.(2009). The relationship among service quality of sports event, participants' satisfaction, re participation intention and word of mouth intention. Tourism Research, 24(5), 175-195.

[14] Lee, H.(2003). Critical review on festival evaluation: based on culture-tourism festival. Tourism Review, 15, 89-112.

[15] Lee, T.K., \& Kim, K.S.(2008). Analysis of visitors' satisfaction factors for regional sport tourism development. Korean Journal of Tourism Research, 22(4), 133-150.

[16] Marine Southeast(2009). BMF watersport report 2008. Marine Research Report.

[17] Ministry of Culture \& Tourism(2003). Development of culture and tourism events' appraisal model. Research Paper.

[18] Mohr, K., Backman, L., Gahan, W., \& Backman, S.(1993). An investigation of festival motivations and event satisfaction by visitor type. Festival Management and Event Tourism, 1(3), 89-97.

[19] Moon, S.H., \& Cho, T.S.(2011). Relations between satisfaction with participation in sport events and district image. The Korean Journal of Physical Education. 50(1), 161-173. 
The Effects of a Marine Leisure Exhibition Event's Appraisal Attributes on Visitors' Satisfaction and Re-visit Intention

[20] Moon, S.J., Kim, M.C., \& Boo, C.S.(2008). A study on evaluation attributes influencing satisfaction and payment intention in Deubul festival of Jeju region. Korean Journal of Hotel Management Research, 17(3), 157-173.

[21] Ryu, C.W.,\& Lee, K.W.(2009). The effects of selection attributes on customer satisfaction of sport event participants. Journal of Sport and Leisure Studies, 36, 323-331.

[22] Yeo, H.K., Oh, H.C., \& Kim, D.H.(2006). A study on the relation of festival participants' evaluation and experience intention on the festival. Convention Research, 6(3), 153-168.

[23] Yoon, S.H.(2009). A study of the derivation of the estimation attributes of the convention centers and of the perception of the importance of people in the convention industry in Korea, China and Japan. Hotel \& Tourism Research, 11(1), 70-90.

Received 12 May 2011

Revised 28 June 2011

Accepted 28 June 2011 